\title{
Effect of dexmedetomidine, midazolam, and propofol on lipopolysaccharide-stimulated dendritic cells
}

\author{
FENG GUO $^{1}$, YING DING $^{2}, \mathrm{XUE} \mathrm{YU}^{3}$ and XIUJUN CAI ${ }^{4}$ \\ ${ }^{1}$ Department of Intensive Care Unit, Sir Run Run Shaw Hospital; ${ }^{2}$ Department of Intensive Care Unit, \\ Sir Run Run Shaw Hospital Xiasha Campus, School of Medicine, Zhejiang University, Hangzhou, Zhejiang 310016; \\ ${ }^{3}$ Department of Medicine, Tengzhou Central People's Hospital, Zaozhuang, Shandong 277500; ${ }^{4}$ Department of General Surgery, \\ Sir Run Run Shaw Hospital, School of Medicine, Zhejiang University, Hangzhou, Zhejiang 310016, P.R. China
}

Received June 13, 2017; Accepted March 9, 2018

DOI: $10.3892 /$ etm.2018.6094

\begin{abstract}
Dexmedetomidine, midazolam and propofol are common sedative drugs used in the intensive care unit. Lipopolysaccharides (LPS) are a potent inducer of human dendritic cells (DCs) maturation and survival, which induces cytokine production. The present study aimed to investigate the effect and mechanisms of sedative drugs on LPS-induced cytokine production in DCs. The mouse bone marrow-derived dendritic DC2.4 cell line was used in the present study. The Cell Counting Kit-8 assay was used to measure the viability of cells. Tumor necrosis factor (TNF)- $\alpha$, interleukin (IL)-1 $\beta$, IL-6, and IL-10 mRNA expression levels and contents were measured using reverse transcription-quantitative polymerase chain reaction and ELISA, respectively. The expression levels of proteins associated with nuclear factor $-\kappa \mathrm{B}(\mathrm{NF}-\kappa \mathrm{B})$ and mitogen activated protein kinase signaling pathways were assessed by western blotting. The three sedatives had different roles on TNF- $\alpha$, IL-1 $\beta$, IL-6, and IL-10 mRNA expression levels and content in DCs. Dexmedetomidine promoted inflammatory cytokine production at high clinical concentrations $(10,1$ and $0.1 \mu \mathrm{M})$, however suppressed them at the lowest clinical concentration $(0.001 \mu \mathrm{M})$, which was associated with $\mathrm{NF}-\kappa \mathrm{B}$ and c-Jun N-terminal kinase (JNK)-mitogen-activated protein kinase (MAPK) signaling. Midazolam inhibited inflammatory cytokine production via suppression of the NF- $\mathrm{B}$ and JNK signaling pathways. Propofol partly inhibited inflammatory cytokine production, including IL-1 $\beta$ and IL-6, and the anti-inflammatory effect may result from inhibition of JNK-MAPK, and enhanced NF- $\mathrm{KB}$ and extracellular signal-regulated kinase-MAPK signaling at clinical
\end{abstract}

Correspondence to: Dr Xiujun Cai, Department of General Surgery, Sir Run Run Shaw Hospital, School of Medicine, Zhejiang University, No. 3 East Qingchun Road, Hangzhou, Zhejiang 310016, P.R. China

E-mail: srrsh_cxj@zju.edu.cn

Key words: dendritic cells, dexmedetomidine, midazolam, propofol, inflammation concentrations. The present study helped to elucidate the function of sedatives in LPS-induced cytokine production in DCs, which will facilitate rational implementation of these sedatives in patients undergoing tracheal intubation with sepsis or multiple organ dysfunction syndrome.

\section{Introduction}

Dexmedetomidine, midazolam, and propofol, sedative drugs commonly used in the intensive care unit, are widely used for critical patients with tracheal intubation; most of these patients suffer from sepsis or severe sepsis. Recently, the effects of these sedative drugs on inflammation have been considered $(1,2)$, and for both clinical and in vitro studies have compared the effects of these three drugs on inflammation models $(3,4)$. Propofol and midazolam has shown anti-inflammatory properties in a variety of experimental models $(1,5)$, while dexmedetomidine, a highly selective agonist of $\alpha 2$-adrenergic receptors, may have a biphasic effect on cells (6).

Dendritic cells (DCs) are one of the crucial immune cells that bridge innate and adaptive immunity, in which DC process antigens during innate immune responses to present them to naïve T-cells, leading to an establishment of adaptive immunity (7). After they are stimulated, immature DCs migrate to the draining lymph node where DCs present the processed antigen peptides to lymphocytes, which then leads to the establishment of adaptive immunity (8). Lipopolysaccharide (LPS), a bacterial endotoxin contributing to sepsis, can stimulate immature DCs and induce an inflammatory response; during this process, the expression of inflammation cytokines, such as tumor necrosis factor (TNF)- $\alpha$, interleukin (IL)-1 $\beta$, IL-6, and IL-10, increases $(9,10)$. Moreover, over-production of cyclooxygenase-2 (COX2) enzymes, which are pro-inflammatory factors, can also be enhanced by LPS $(11,12)$. The nuclear factor- $\kappa \mathrm{B}(\mathrm{NF}-\kappa \mathrm{B})$ and mitogen-activated protein kinase (MAPK) pathways play a vital role in this inflammatory response $(10,13)$.

In vitro studies on the effect of sedatives oninflammation have mostly concentrated on the effects on macrophages $(6,14,15)$ and microglia (16), and few have considered the effects on DCs $(17,18)$. Therefore, in this study, we investigated the effect of dexmedetomidine, midazolam, and propofol, in doses based 
on the typical blood levels achieved clinically, on the production of inflammatory mediators in LPS-activated DCs, and then we explored the underlying mechanism. We show that the three sedatives could affect LPS-induced inflammation through different pathways.

\section{Materials and methods}

Cell culture. Mouse bone marrow-derived DCs (named DC2.4 cell) were kindly donated by Cheng Hao (Department of Dermatology, Medical College of Zhejiang University, Sir Run Run Shaw Hospital, Hangzhou, China) (19). DC2.4 cells were grown in Dulbecco's modified Eagle's medium (DMEM) supplemented with $10 \%$ fetal bovine serum (FBS; Gibco; Thermo Fisher Scientific, Inc., Waltham, MA, USA), in culture dishes (60x15 mm; Corning Inc., Corning, NY, USA) at $37^{\circ} \mathrm{C}$ with $5 \% \mathrm{CO}_{2}$ in a humidified chamber. The culture medium was changed every day for routine culture and each treatment was carried out when the cells reached $80 \%$ confluence (6).

Experimental protocols. DC2.4 cells were stimulated with LPS (Escherichia coli; serotype 055:B5; Sigma-Aldrich; Merck KGaA, Darmstadt, Germany, $10 \mathrm{mg} / \mathrm{ml}$ ) to induce the expression of inflammatory molecules. A total of 26 groups were employed. Two groups of DC2.4 cells, treated with phosphate-buffered saline (PBS; denoted as the control group) or LPS $(1 \mu \mathrm{g} / \mathrm{ml}$, denoted as the L group), which were served as the negative or positive controls, respectively. To elucidate the effect of dexmedetomidine (Heng Riu Inc., Jiangsu, China), midazolam (Nhwa Inc., Jiangsu, China), and propofol (Sigma-Aldrich; Merck KGaA) on DCs, 12 groups of DC2.4 cells were divided into 12 groups and treated with different concentrations of dexmedetomidine $(0.5,0.1,0.01$, or $0.001 \mu \mathrm{M})$, midazolam $(50,10,1$, or $0.1 \mu \mathrm{M})$, or propofol $(100,50,15$, or $1 \mu \mathrm{M})$ respectively, which were named as group of D1, D2, D3, D4, M1, M2, M3, M4, P1, P2, P3, P4, respectively. To compare the effect of dexmedetomidine, midazolam, and propofol on LPS-stimulated DCs, DC2.4 cells were divided into 12 groups again and treated with LPS $(1 \mu \mathrm{g} / \mathrm{ml})$ plus different concentrations of dexmedetomidine $(0.5,0.1,0.01$, or $0.001 \mu \mathrm{M}$; denoted as L-D1, L-D2, L-D3, and L-D4, respectively), LPS plus midazolam $(50,10,1$, or $0.1 \mu \mathrm{M}$; denoted as L-M1, L-M2, L-M3, and L-M4, respectively), or LPS plus propofol $(100,50,15$, or $1 \mu \mathrm{M}$; denoted as L-P1, L-P2, L-P3, and L-P4, respectively). These dosages included clinical dosages (0.001-1 $\mu \mathrm{M}$ dexmedetomidine, $0.1-10 \mu \mathrm{M}$ midazolam, and 1-50 $\mu \mathrm{M}$ propofol) as well as a supra-concentration of every drug $(0.5 \mu \mathrm{M}$ dexmedetomidine, $50 \mu \mathrm{M}$ midazolam, and $100 \mu \mathrm{M}$ propofol) $(18,20-22)$. The concentration of LPS for all treatments was $1 \mu \mathrm{g} / \mathrm{ml}$.

Cell viability assay. The cell counting kit- 8 was used to determine cell viability (CCK-8, Yiyuan Biotechnologies, Guangzhou, China), which indicated the mitochondrial enzyme activity. To examine the effect of the tested drugs on DC2.4 cell viability, the DC2.4 $\left(3 \times 10^{4}\right.$ cells $\left./ \mathrm{ml}\right)$ were cultured with DMEM medium containing 10\% FBS in flat-bottom 96-well plates $(200 \mu \mathrm{l} /$ well $)$ and overnight at $37^{\circ} \mathrm{C}$, in a humidified chamber with $5 \% \mathrm{CO}_{2}$. The cultured medium was replaced by the medium containing LPS and/or anesthetic drugs, and then cells were cultured for $24 \mathrm{~h}$. After treatment, a new medium replaced the cultured medium, adding $20 \mu \mathrm{l} /$ well of CCK-8 solution into each well, and followed by incubation at $37^{\circ} \mathrm{C}$ for $2 \mathrm{~h}$. The absorbance was measured at $490 \mathrm{~nm}$, with the correction wavelength set at $650 \mathrm{~nm}$. The cell viablity $(\%)=\left(\mathrm{OD}_{\text {drug }}-\mathrm{OD}_{\text {blank control }}\right) /\left(\mathrm{OD}_{\text {control }}-\mathrm{OD}_{\text {blank control }}\right) \times 100 \%$. The the blank control was that had no cell while contained medium and CCK-8. All experiments were performed in triplicate. Data are representative of the mean and standard deviation of three replicates within an experiment.

Reverse transcription-quantitative polymerase chain reaction $(R T-q P C R)$. In order to observe the changes in inflammatory molecules at mRNA level, we used RT-qPCR. We extracted total RNA from treated DC2.4 cells using an Ultrapure RNA kit (CWBIO, Beijing, China) according to the manufacturer's protocol. In brief, we synthesized first-strand cDNA with a HiFiScript 1st Strand cDNA Synthesis kit (CWBIO). Then, we performed RT-qPCR with SYBR-Green (SYBR Premix ExTaq GC; Takara Biotechnology Co., Ltd., Dalian, China) on a LightCycler480 Real-Time PCR System. The primer sequences were as follows: TNF- $\alpha$-F: 5 '-AGGGTCTGG GCCATAGAACT-3', TNF- $\alpha-R:$ 5'-CCACCACGCTCTTCT GTCTAC-3'; IL-1ß-F: 5'-TGGCAACTGTTCCTGAACTCA A-3', IL-13-R: 5'-AGCAGCCCTTCATCTTTTGG3'; IL-6-F: 5'-AGTTGCCTTCTTGGGACTGA3', IL-6-R: 5'-TCCACG ATTTCCCAGAGAAC3'; IL-10-F: 5'-GCCAAGCCTTAT CGGAAATG3', IL-10-R: 5'-CACCCAGGGAATTCAAAT GC3'; 36B4-F: 5'-GCCCTGCACTCTCGCTTTCT-3', 36B4-R: 5'-CAACTGGGCACCGAGGCAACAGTTG-3' (23). The RT-PCR reaction involved initial denaturation $\left(95^{\circ} \mathrm{C}, 30 \mathrm{sec}\right)$, followed by 42 cycles each consisting of denaturation $\left(95^{\circ} \mathrm{C}\right.$, $5 \mathrm{sec})$, and extension $\left(60^{\circ} \mathrm{C}, 30 \mathrm{sec}\right)$, and then a final extension step at $95^{\circ} \mathrm{C}$ for $30 \mathrm{sec}$.

Cytokine assays. To test the inflammatory cytokine levels, DC2.4 cells were cultured in 96-well plates $(200 \mu \mathrm{l} /$ well $)$ at $3 \times 10^{4}$ cells $/ \mathrm{ml}$ overnight. With LPS treatment, the detection time are set at $0,0.5,1,2,4,6,8,12,18$ and $24 \mathrm{~h}$. The highest expression levels of IL-6, IL-10, TNF- $\alpha$ and IL- $1 \beta$ were observed at 4, 6, 2 and $2 \mathrm{~h}$, respectively. The pre-experiment showed that, the difference between the TNF- $\alpha /$ IL-1 $\beta$ expression level at $2 \mathrm{~h}$ and at the peak time (respective, 4 and $6 \mathrm{~h}$ ) is small, while their expression level at $2 \mathrm{~h}$ LPS treatment are obviously higher than the blank group (data not shown). In order to unify experimental environment and convenient experiment, $2 \mathrm{~h}$ was selected for subsequent experiments. So the cell was all cultured with drugs for $2 \mathrm{~h}$. After adding LPS $(1 \mu \mathrm{g} / \mathrm{ml})$ and/or anesthetic drugs in the culture media for $2 \mathrm{~h}$, the culture media were renewed and cells were cultured further for $18 \mathrm{~h}$. And then the media were collected and stored at $-80^{\circ} \mathrm{C}$ until required for analysis. Enzyme-linked immunosorbent assay (ELISA) kits for mouse TNF- $\alpha$, IL-6, and IL-10 (R\&D Systems, Inc., Minneapolis, MN, USA) were used according to the manufacturer's instructions. IL- $1 \beta$, as an endocellularly secreted inflammatory cytokine, was barely secreted to the outside of cells after LPS stimulation. When the cells were ruptured by repeated freezing and thawing (24), and IL-1 $\beta$ could be detected using an IL-1 $\beta$ Colorimetric ELISA kit (R\&D Systems, Inc.). According to the ELISA reagents assay 
kit protocols, the minimum detection dose ranges for TNF- $\alpha$, IL-6, IL-10 and IL-1 $\beta$ were $0.36-7.21,1.3-1.8,0.46-4.80$ and $0.652-5.22 \mathrm{pg} / \mathrm{ml}$, and the sensitivity of the ELISA for them were $7.21,1.8,5.22$ and $4.8 \mathrm{pg} / \mathrm{ml}$, respectively. The concentrations of TNF- $\alpha$, IL- 6 , IL-10, and IL-1 $\beta$ were respectively assayed using a microplate reader set to $450 \mathrm{~nm}$, with the correction wavelength set at $540 \mathrm{~nm}$. All experiments were performed in triplicate. Data are representative of the mean and standard deviation of three replicates within an experiment.

Western blot analysis. Western blotting was used to assess the protein expression of COX2, I $\kappa \mathrm{B}-\alpha$, ERK-MAPK, p38-MAPK, and JNK-MAPK in DC2.4 cells. Based on a pre-experiment, 15 min was chosen as the treatment time for all proteins, except for COX2, whose treatment time was $10 \mathrm{~h}$. In short, after drug treatments, proteins were extracted from the cultured cells using RIPA buffer (Boster, Wuhan, China) containing PMSF (BOSTER) and phosphatase inhibitors (Boster). Protein concentrations were quantified using a BCA protein assay kit (Boster). Equal amounts of total protein were separated electrophoretically by SDS-PAGE and the corresponding blots probed with the relevant primary antibodies (Cell Signaling Technology, Inc., Danvers, MA, USA), followed by incubation with appropriate secondary antibodies. The target proteins were then visualized using a chemiluminescence method (ECL kit; Amersham Biosciences, Foster City, CA, USA) and imaged with a digital imaging system (Image Quant LAS-4000; Fujifilm, Tokyo, Japan). Multi-Gauge Software was used for determining band densities (Fujifilm).

Statistical analysis. Results are representative of at least 3 independent experiments. The data are presented as mean \pm SEM and were analyzed using the GraphPad Prism 5 (GraphPad Software, Inc., La Jolla, CA, USA) and SPSS software (SPSS, Inc., Chicago, IL, USA). The experiments were analyzed using One-way analysis of variance (ANOVA) with Dunnett's test for the comparaison of more groups of data and Unpaired Student t-test for the comparaison of two groups of data. In all cases, $\mathrm{P}<0.05$ was considered to indicate a statistically significant difference.

\section{Results}

Effect of sedatives on the DCs viability. To test the toxicity of dexmedetomidine, midazolam, propofol, and LPS on DCs, the DCs were cultured with these drugs and LPS, respectively, and then the cell viability was assayed using a CCK-8 kit. Compared with the negative control group, the DC2.4 cells viability has no significantly changes in LPS group or in LPS-combined respectively dexmedetomidine, midazolam, and propofol groups (Fig. 1).

Effect of sedatives on LPS-induced cytokines. The pre-experiment showed that the TNF- $\alpha$, IL- $1 \beta$, IL- 6 , and IL-10 mRNA expression peaked at different times in response to treatment, but their expression levels were all elevated after LPS treatment for $2 \mathrm{~h}$. So the cell was all cultured with drugs for $2 \mathrm{~h}$. Compared with the negative control, there was a significant increase of the TNF- $\alpha$, IL-1 $\beta$, IL-6, and IL-10 mRNA expression in LPS-treated cell (all $\mathrm{P}<0.05)$. However, the only

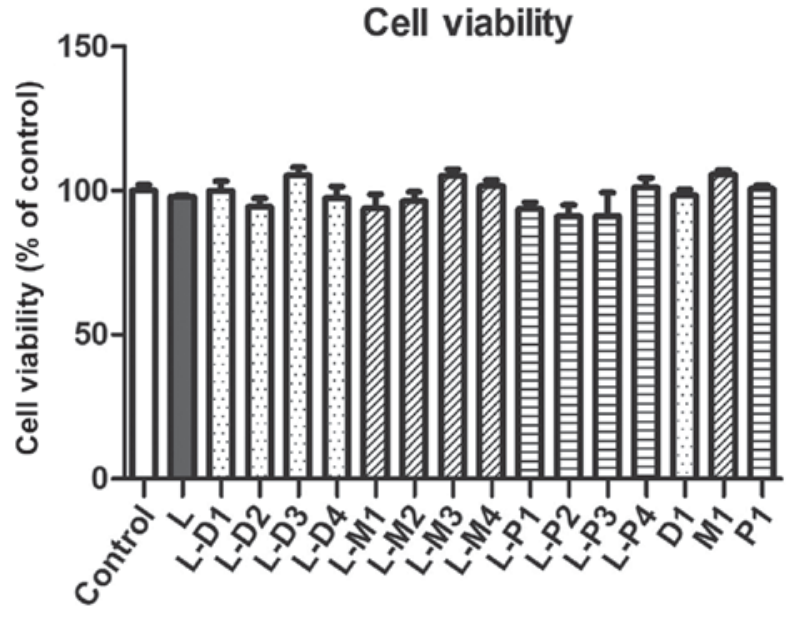

Figure 1. Effects of lipopolysaccharides with or without different anesthetic drugs on dendritic cell viability.

dexmedetomidine, midazolam, and propofol did not affect their expression (data not shown).

Upon co-treatment with LPS, dexmedetomidine did not significantly affect the LPS-induced TNF- $\alpha$, IL-1 $\beta$, IL-6 and IL-10 mRNA expression at the used four concentrations ( $\mathrm{P}>0.05$, Fig. 2). However, midazolam, at all four concentrations, markedly inhibited LPS-induced IL-6 mRNA expression (Fig. 2C). The inhibition ratio of midazolam was up to $84.3 \pm 7.6,51.6 \pm 8.7,20.6 \pm 9.2$, and $31.3 \pm 8.0 \%$ at $50,10,1$ and $0.1 \mu \mathrm{M}$, respectively.

Midazolam at a concentration of 10 and $50 \mu \mathrm{M}$ also significantly inhibited the LPS-induced IL-1 $\beta$, IL-6 and IL-10 expression. The LPS-induced IL-6 and IL-10 expression were not markedly affected by propofol at any of the tested concentrations (Fig. 2C and D). Moreover, as Fig. 2A and B showed that propofol did not affect the LPS-enhanced TNF- $\alpha$ and IL-1 $\beta$ expression at both of the highest $(100 \mu \mathrm{M})$ and lowest concentrations $(1 \mu \mathrm{M})$, while propofol at 50 and $30 \mu \mathrm{M}$ could inhibit the induced TNF- $\alpha$ expression by $24.7 \pm 7.2$ and $20.7 \pm 9.1 \%$, respectively. Additionally, the enhanced IL-1 $\beta$ expression was significantly suppressed by propofol at 50 and $15 \mu \mathrm{M}$ with the inhibition rate of $41.1 \pm 16.5$ and by $28.9 \pm 17.5 \%$, respectively, but this did not reach statistical significance.

Effect of sedatives on LPS-induced cytokines levels. As shown in Fig. 3, LPS could enhance significantly TNF- $\alpha$, IL-1 $\beta$, and IL-6 levels in DCs $(\mathrm{P}<0.05)$. In addition to the $1 \mu \mathrm{M}$ dexmedetomidine that could inhibit LPS-induced IL-1 $\beta$ and IL- 6 levels with the inhibition ratio of $24.7 \pm 7.2$ and $17.5 \pm 5 \%(\mathrm{P}<0.0)$, respectively, the other used concentrations did not affect TNF- $\alpha$, IL-1 $\beta$, and IL- 6 levels. Midazolam could inhibit LPS-enhanced IL- 6 protein expression at four used concentration $(50 \mu \mathrm{M}: 90.7 \pm 4.9 \%, 10 \mu \mathrm{M}: 45.9 \pm 12.3 \%$, $1 \mu \mathrm{M}: 21.7 \pm 7.4 \%, 0.1 \mu \mathrm{M}: 25.5 \pm 4.42 \%)$. A similar negative effect on LPS-induced IL-6 expression was seen after propofol treatment at $15 \mu \mathrm{M}(\mathrm{L}-\mathrm{P} 3)$ and $1 \mu \mathrm{M}(\mathrm{L}-\mathrm{P} 4)$, with a reduction by $7.6 \pm 2.5$ and $21.5 \pm 3.6 \%$, respectively. Propofol did not significantly affect the LPS-induced TNF- $\alpha$ levels, while midazolam could significantly suppress it by $49.9 \pm 13.3 \%$ at $50 \mu \mathrm{M}$ and by $28.2 \pm 10.3 \%$ at $10 \mu \mathrm{M}$, and non-significantly by $13.6 \pm 7.6 \%$ at $1 \mu \mathrm{M}$ and $17.0 \pm 7.8 \%$ at $0.1 \mu \mathrm{M}$. A similar 

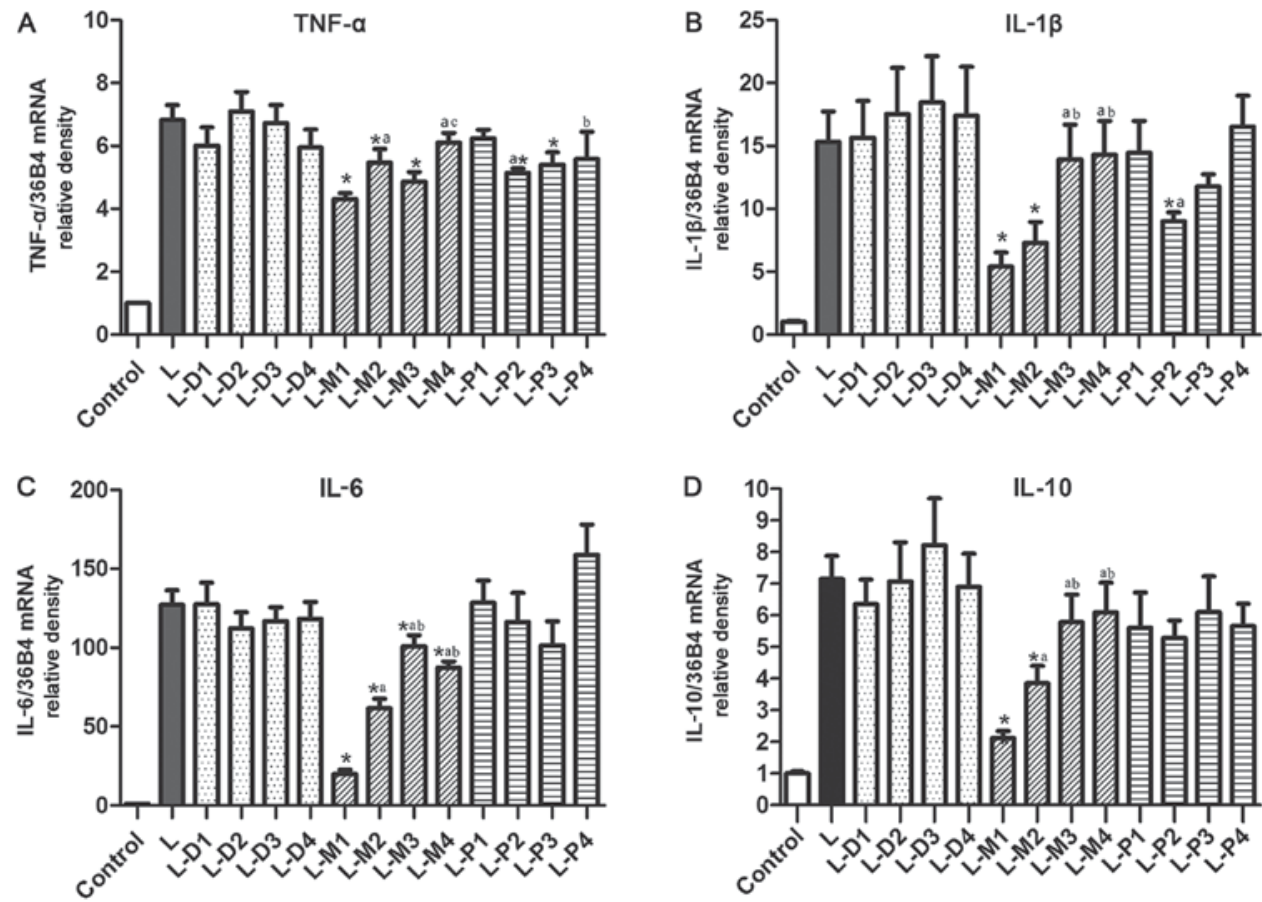

Figure 2. Effects of dexmedetomidine, midazolam, and propofol on LPS-enhanced cytokine mRNA levels. (A) The TNF- $\alpha$ mRNA levels. (B) The IL-1 mRNA levels. (C) The IL-6 mRNA levels. (D) The IL-10 mRNA levels. "P $<0.05$ vs. L group, ${ }^{a} \mathrm{P}<0.05$ vs. L-D1, L-M1 or L-P1 group, respectively. ${ }^{b} \mathrm{P}<0.05$ vs. L-D1, L-M1 or L-P1 group, respectively. ' ${ }^{~} \mathrm{P}<0.05$ vs. L-D1, L-M1 or L-P1 group, respectively. LPS, Lipopolysaccharides; TNF, tumor necrosis factor; IL, interleukin.
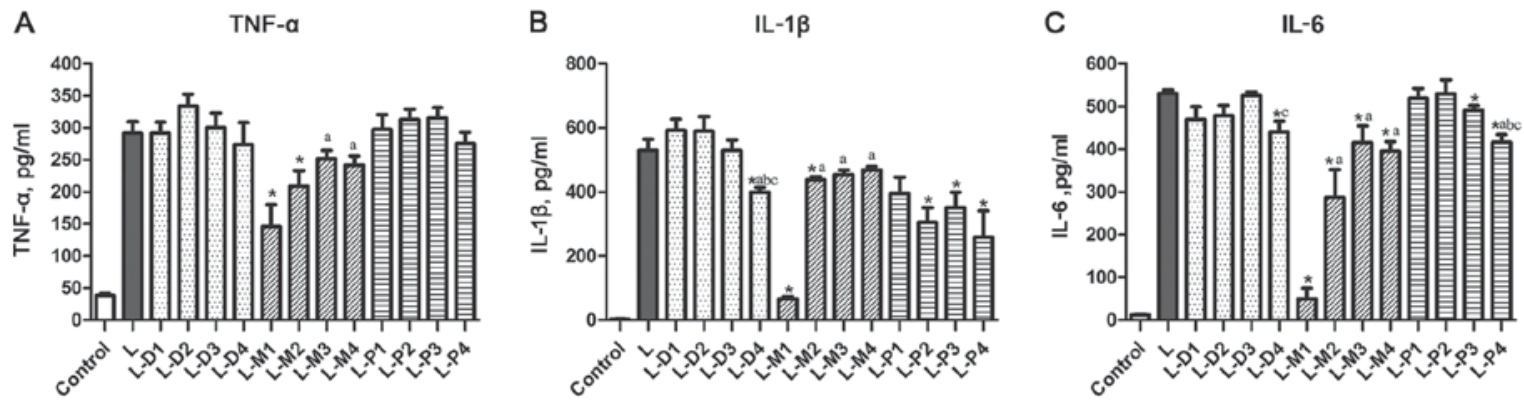

Figure 3. Effects of dexmedetomidine, midazolam, and propofol on LPS-enhanced cytokine levels. (A) The TNF- $\alpha$ mRNA levels. (B) The IL-1 $\beta$ mRNA levels (C) The IL-6 mRNA levels. "P<0.05 vs. L group, ${ }^{a} \mathrm{P}<0.05$ vs. L-D1, L-M1 or L-P1 group, respectively. ${ }^{b} \mathrm{P}<0.05$ vs. L-D1, L-M1 or L-P1 group, respectively. ${ }^{\mathrm{C}} \mathrm{P}<0.05$ vs. L-D1, L-M1 or L-P1 group, respectively. LPS, Lipopolysaccharides; TNF, tumor necrosis factor; IL, interleukin.

inhibitory effect could also been seen in midazolam treatment on LPS-induced IL- $1 \beta$ levels by $87.3 \pm 6.7 \%$ at $50 \mu \mathrm{M}$ and by $17.2 \pm 6.8 \%$ at $10 \mu \mathrm{M}$, and non-significantly by $14.3 \pm 7.1 \%$ at $1 \mu \mathrm{M}$ and by $11.4 \pm 6.9 \%$ at $0.1 \mu \mathrm{M}$. LPS-enhanced IL- $1 \beta$ levels could also be suppressed by propofol at 50,15 and $1 \mu \mathrm{M}$ by $47.4 \pm 10.9,33.7 \pm 11.2$, and $51.1 \pm 16.8 \%$, respectively. Propofol at $100 \mu \mathrm{M}$ also showed an inhibitory effect on reducing LPS-induced IL-1 $\beta$ by $25.3 \pm 11.6 \%$, but it was not statistically significant. Additionally, we found that IL-10 levels in all treatment groups were below the detection limit (data not shown).

Effect of sedatives on the LPS-stimulated NF- $\kappa B$ and MAPK pathways. Western blotting was used to assess the protein expression of COX2, IкB- $\alpha$, ERK-MAPK, p38-MAPK, and JNK-MAPK in DC2.4 cells. Based on a pre-experiment, 15 min was chosen as the treatment time for all proteins, except for COX2, whose treatment time was $10 \mathrm{~h}$. COX2, phospho-P38, phospho-ERK, and phospho-JNK expression was low in the control group, but was clearly enhanced by LPS treatment (Fig. 4A). Dexmedetomidine, midazolam, and propofol could not change the basal expression levels of these proteins (data not shown).

As showed in Fig. 4A, midazolam inhibited LPS-enhanced COX 2 protein expression at concentrations of 10 and $50 \mu \mathrm{M}$. Co-treatment with LPS and dexmedetomidine at 0.01, 0.1, and $1 \mu \mathrm{M}$ promoted COX2 protein expression. Similarly, co-treatment with LPS and propofol at concentrations of 1,15 , and $30 \mu \mathrm{M}$ promoted COX2 expression. However, the effect of propofol at $50 \mu \mathrm{M}$ actually had an inhibitory effect. I $\mathrm{B}-\alpha$, a crucial NF- $\kappa \mathrm{B}$ component, has a suppressive effect on inflammation. In particular, midazolam at 10 and $50 \mu \mathrm{M}$ suppressed the LPS-mediated reduction in the expression

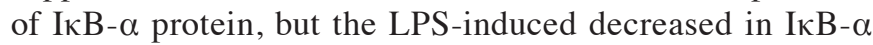


A
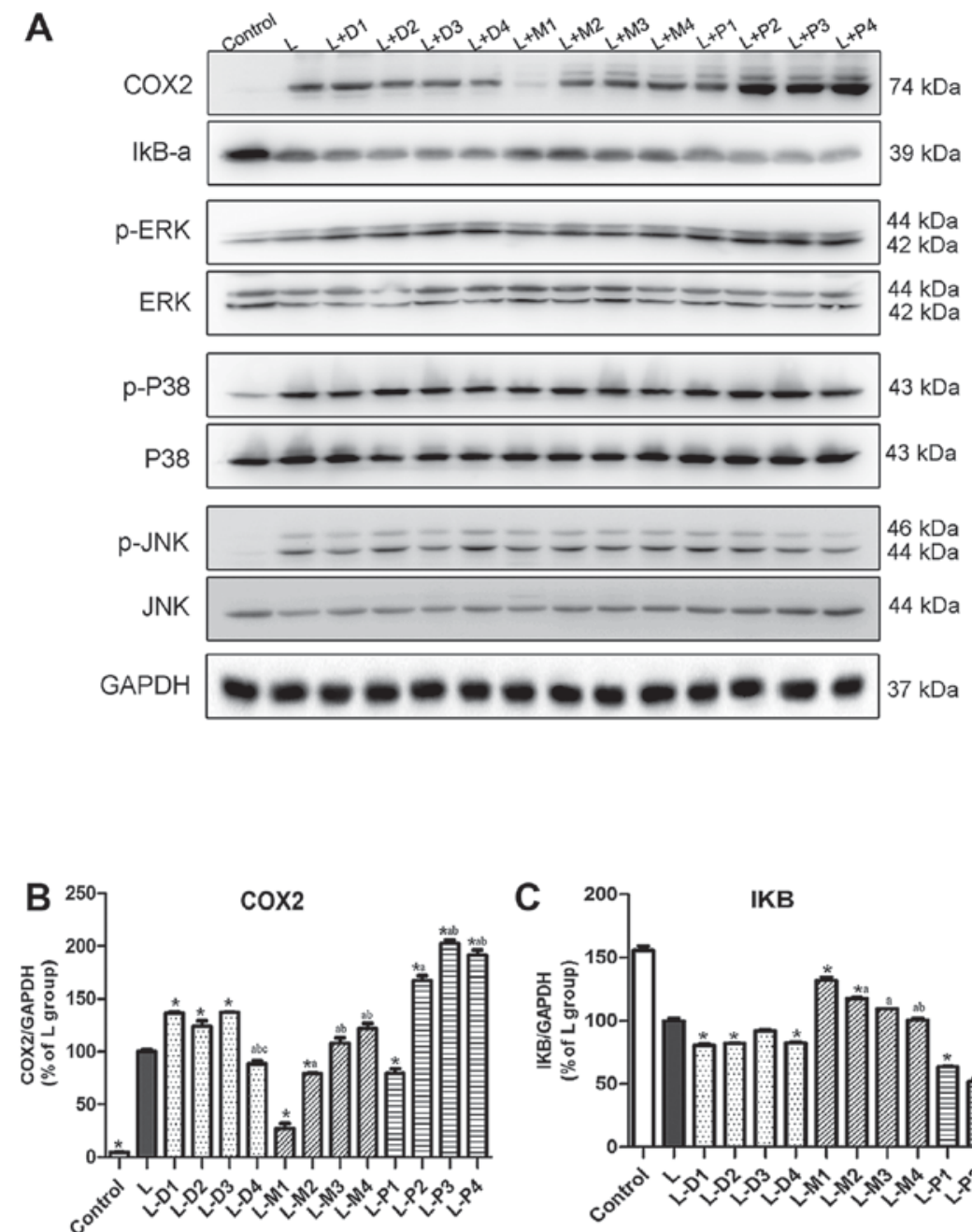

C ${ }^{200} 7 \quad$ IKB
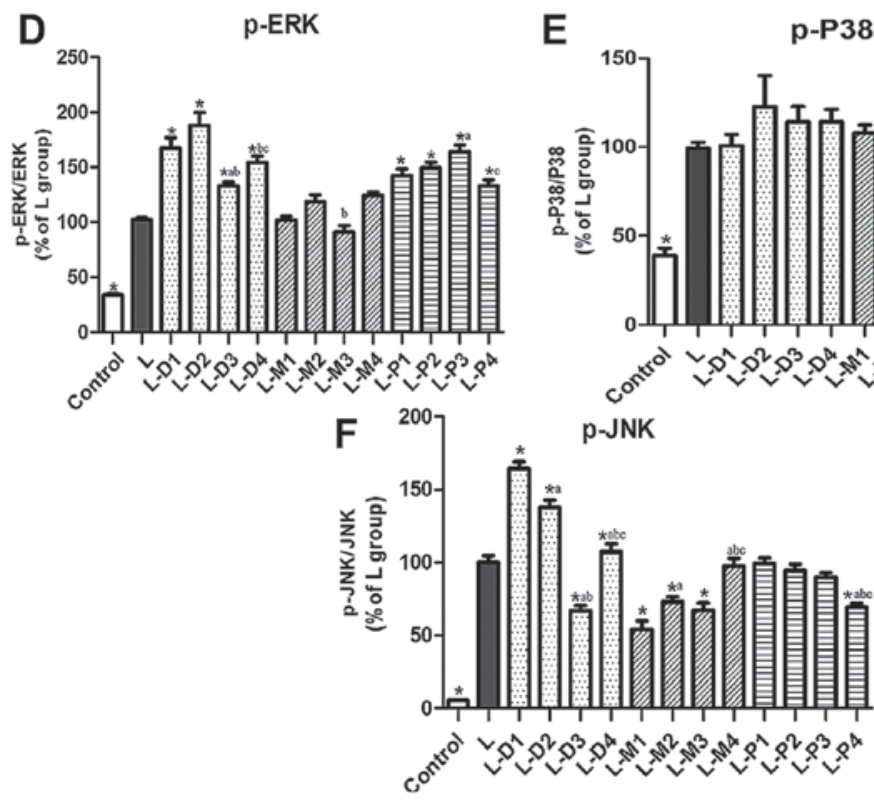

Figure 4. Effect of dexmedetomidine, midazolam, and propofol on LPS-stimulated NF-кB and MAPK pathways. (A) The western blot of COX2, IкB- $\alpha$, p-ERK, p-p38 and p-JNK. (B-F) The graphics with the data from COX2, IкB- $\alpha$, p-ERK, p-p38 and p-JNK protein level. ${ }^{*} \mathrm{P}<0.05$ vs. $\mathrm{L}$ group, ${ }^{\mathrm{a}} \mathrm{P}<0.05$ vs. L-D1, L-M1 or L-P1 group, respectively. ${ }^{b} \mathrm{P}<0.05$ vs. L-D1, L-M1 or L-P1 group, respectively. ${ }^{\mathrm{C}} \mathrm{P}<0.05$ vs. L-D1, L-M1 or L-P1 group, respectively. LPS, Lipopolysaccharides; NF-кB, nuclear factor-кB; TNF, tumor necrosis factor; IL, interleukin; COX2, cyclooxygenase-2; p-, phospho; ERK, extracellular signal-regulated kinase; JNK, c-Jun N-terminal kinase.

protein was enhanced by both dexmedetomidine and propofol at all tested concentrations.
In order to explore whether MAPK signaling participates in the inflammatory process, the three main 
proteins involved in MAPK signaling, viz., phospho-p38, phospho-ERK, and phospho-JNK, as well as their reference proteins, were investigated. LPS could enhance the expression of phospho-ERK, phospho-p38, and phospho-JNK, but none of the three anesthetic drugs changed the basal protein secretion.

While midazolam did not significantly affect the expression of LPS enhanced phospho-ERK, both dexmedetomidine and propofol promoted this expression at the used four concentrations. Phospho-JNK expression, induced by LPS, could be inhibited by midazolam (at 50,10 and $1 \mu \mathrm{M})$ and propofol $(1 \mu \mathrm{M})$. and was enhanced by dexmedetomidine (at 1, 0.1 and $0.001 \mu \mathrm{M}$ ). However, this enhancement by dexmedetomidine was reduced at a low concentration, and at $0.01 \mu \mathrm{M}$, dexmedetomidine rather had an inhibitory effect. Furthermore, none of the three drugs affected the LPS-enhanced expression of phospho-p38.

\section{Discussion}

Recently, the effects of sedative drugs on inflammation have become a matter of interest $(1,2)$. Propofol is an intravenous anesthetic that is widely used for anesthesia and sedation, and Inada et al reoprted that intravenous anesthetic propofol suppresses prostaglandin E2 production in murine DC (25). Dexmedetomidine has an effect on the migratory capacity of DCs both in vitro and in vivo (17). Generally, TNF- $\alpha$, IL-1 $\beta$, and IL-6 are regarded as important pro-inflammatory cytokines, while IL-10 is considered as an anti-inflammatory cytokine (26-28). This study aimed to investigate the effect of dexmedetomidine, propofol and midazolam on pro-inflammatory cytokines production in LPS-induced DCs are lacking.

Our study demonstrated that dexmedetomidine has a biphasic effect that enhanced inflammation at high clinical concentrations $(10,1$, and $0.1 \mu \mathrm{M})$ and inhibited inflammation at the lowest clinical concentration $(0.001 \mu \mathrm{M})$, and this mechanism was related to NF- $\mathrm{kB}$ and JNK-MAPK signalling pathway. However, beyond this concentration, dexmedetomidine did not significantly influence pro-inflammatory or anti-inflammatory cytokine expression that had been enhanced by LPS stimulation of DCs. Midazolam at the highest clinical dosage and 5 times this dose concentration-dependently inhibited LPS-induced TNF- $\alpha$, IL- $1 \beta$, and IL- 6 expression at mRNA and protein levels. Interestingly, IL-10 expression was also inhibited by midazolam. This indicated that midazolam-mediated inhibition of the maturation of DCs may play a role in its anti-inflammatory action (18). Propofol can partly inhibit LPS-induced expression of pro-inflammatory cytokines, such as IL-1 $\beta$ and IL-6, and its anti-inflammatory effect may be achieved by inhibiting JNK-MAPK signalling, and enhancing NF- $\mathrm{KB}$ and ERK-MAPK signaling at clinical concentrations.

The numbers of reports about the effects of propofol on inflammation outnumber those of the other two sedatives (29). Though the inhibit effect of propofol on cytokine were similar seen in many previous study, our study shows that propofol could enhanced LPS-induced COX2, that may be because of the difference cells. As antigen-processing and presenting cells, activation of DCs in inflammation was earlier than others in their study, like macrophage and microglia (30-32). Moreover, the concentration of propofol based on clinical blood concentration in our study was lower than the study on DC (33).

Inflammatory cytokines are closely associated with inflammatory signaling, particularly with signalling via the $\mathrm{NF}-\kappa \mathrm{B}$ and MAPK pathways. We investigated whether the drugs studied influenced either or both pathways. In order to

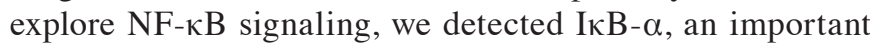
component of the NF- $\mathrm{kB}$ complex that can be degraded from the complex, by western blotting. Transcription factors such as $\mathrm{NF}-\kappa \mathrm{B}$ also mediate the expression of some inducible genes, such as the gene encoding COX-2. When LPS binds to its target protein on the surface of cells, it induces signaling via

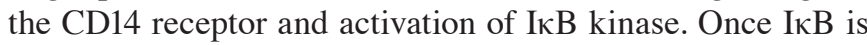

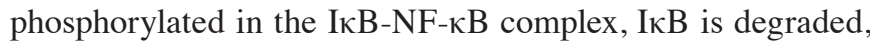
and the free NF- $\kappa \mathrm{B}$ translocates from the cytoplasm into the nucleus where it induces $C O X 2$ expression $(12,34)$. We showed that dexmedetomidine in high concentration could increase IкB- $\alpha$ degradation and enhance LPS-induced COX-2 expression. Similar effects were seen after co-treatment of cells with propofol at clinically relevant concentrations and LPS, but the suppressive effect of propofol was much more marked than that of dexmedetomidine. In contrast, co-treatment of cells with LPS and midazolam markedly inhibited the NF- $\mathrm{KB}$ signaling, by suppressing I $\mathrm{K} \mathrm{B}-\alpha$ degradation, and thereby decreasing the expression of $\mathrm{COX} 2$.

ERK, p38, and JNK protein are three different but important proteins in the MAPK signaling pathway (35). Our study corroborated data from a previous study, which showed that LPS could enhance the expression of ERK-MAPK, p38-MAPK, and JNK-MAPK markedly in DCs (13). However, we show for the first time that dexmedetomidine could enhance the LPS-induced ERK and JNK signaling at a high clinical concentration. JNK-MAPK also contributed to the anti-inflammatory effect of midazolam. In our study, propofol enhanced ERK-MAPK, but inhibited JNK-MAPK signaling. LPS-stimulated p38 MAPK signaling was not markedly changed by an of the three drugs.

Interestingly, after stimulation of DCs with LPS, a significant enhancement of COX-2 protein expression and NF- $\mathrm{KB}$ signalling could be seen with treatment with high clinical concentrations of dexmedetomidine, but the cytokine levels were not markedly affected. Two reasons may account for this phenomenon. First, the expression of cytokines is regulated by many factors besides the NF- $\mathrm{kB}$ pathway, such as their inducer genes, or their levels per se $(11,36)$. Second, beside binding to the highly selective a2-adrenergic receptors, dexmedetomidine can also bind to other kinds of receptors that could affect inflammation in the opposite direction, as may be supported by the biphasic effect noted in this and a previous study (6). Furthermore, as also noted in previous studies, propofol had a partial and slightly anti-inflammatory effect on DCs. For the first time, our study found that this effect may be realized through suppression of the JNK pathway, which perhaps inhibits maturation of DCs (37). However, it should be mentioned that COX-2, NF- $\kappa B$, and ERK-MAPK were enhanced significantly at the same time. Previous studies had reported different effects of ERK-, Ep38-, and JNK-MAPKs (13). It is possible that, as with dexmedetomidine, other kinds of receptors could be involved in the inflammatory effects. The difference may also be related Eto the specific function of DCs, viz., their 
antigen-processing and -presenting capacity. It may be beneficial to have a weak response to LPS-induced inflammation at first. This may account for the anti-inflammatory response in individuals with infection who are receiving dexmedetomidine or propofol, as compared with midazolam and other sedatives $(3,38,39)$.

The study had some limitations. Firstly, this study employed a transformed DC line of murine origin (DC2.4 cells) rather than fresh murine or human DCs. Secondly, although the mechanism underlying the effect of the sedative on inflammation was investigated, the mechanism was not fully elucidated, as specific antagonists or inhibitors of the relevant factors were not employed. In the future, studies should make use of selective antagonists against the sedatives, or the NF- $\kappa$ B and MAPK pathways. Moreover, as antigen-processing and -presenting cells, the migratory capacity of DCs and cell-surface molecules related to their maturity were not investigated, and should be studied in the future.

In conclusion, this study yielded a number of novel insights. i) Midazolam can markedly inhibit LPS-induced inflammatory responses of DCs, and the NF- $\mathrm{BB}$ and JNK-MAPK pathways are suppressed during this process. ii) Dexmedetomidine has a biphasic effect that enhanced inflammation at high clinical concentrations $(10,1$, and $0.1 \mu \mathrm{M})$ and inhibited inflammation at the lowest clinical concentration $(0.001 \mu \mathrm{M})$, and this mechanism was related to NF- $\mathrm{NB}$ and JNK-MAPK signalling. iii) Propofol can partly inhibit LPS-induced expression of pro-inflammatory cytokines, such as IL-1 $\beta$ and IL-6, and its anti-inflammatory effect may be achieved by inhibition of JNK-MAPK, and enhanced NF- $\mathrm{BB}$ and ERK-MAPK signaling, at clinical concentrations. iv) Although both midazolam and propofol at clinical dosages show anti-inflammatory properties in LPS-induced inflammation, which of the former was more marked. Thus, this study helped to elucidate the function of sedatives in inflammation. In addition, it facilitates rational implementation of these three sedatives in patients undergoing tracheal intubation with sepsis or multiple organ dysfunction syndrome.

\section{Acknowledgements}

The authors would like to thank Wang Qi, Zheng Libin and Luo Jingfeng (Department of Central Laboratory, Sir Run Run Shaw Hospital, School of Medicine, Zhejiang University, Hangzhou, China) for their technical support.

\section{Funding}

The present study was supported by The Science Technology Department of Zhejiang Province, China (grant no.2012C33039).

\section{Availability of data and materials}

The datasets used and/or analyzed during the current study are available from the corresponding author on reasonable request.

\section{Authors' contributions}

FG conceived and designed the study, and drafted the manuscript. YD collected the data and XY analyzed the data. XC performed the experiments, reviewed and edited the manuscript. All authors read and approved the final manuscript.

\section{Ethics approval and consent to participate}

Not applicable.

\section{Consent for publication}

Not applicable.

\section{Competing interests}

The authors declare that they have no competing interests.

\section{References}

1. Yuki K, Soriano SG and Shimaoka M: Sedative drug modulates T-cell and lymphocyte function-associated antigen-1 function. Anesth Analg 112: 830-838, 2011.

2. Pandharipande PP, Sanders RD, Girard TD, McGrane S, Thompson JL, Shintani AK, Herr DL, Maze M and Ely EW; MENDS investigators: Effect of dexmedetomidine versus lorazepam on outcome in patients with sepsis: An a priori-designed analysis of the MENDS randomized controlled trial. Crit Care 14: R38, 2010.

3. Ruokonen E, Parviainen I, Jakob SM, Nunes S, Kaukonen M, ShepherdST,Sarapohja T, Bratty JR and Takala J; 'Dexmedetomidine for Continuous Sedation' Investigators: Dexmedetomidine versus propofol/midazolam for long-term sedation during mechanical ventilation. Int Care Med 35: 282-290, 2009.

4. Jung HS, Joo JD, Jeon YS, Lee JA, Kim DW, In JH, Rhee HY and Choi JW: Comparison of an intraoperative infusion of dexmedetomidine or remifentanil on perioperative haemodynamics, hypnosis and sedation and postoperative pain control. J Int Med Res 39: 1890-1899, 2011.

5. Roquilly A, Josien R and Asehnoune K: Midazolam impairs immune functions: It's time to take care of dendritic cells. Anesthesiology 114: 237-238, 2011.

6. Lai YC, Tsai PS and Huang CJ: Effects of dexmedetomidine on regulating endotoxin-induced up-regulation of inflammatory molecules in murine macrophages. J Surg Res 154: 212-219, 2009.

7. Lipscomb MF and Masten BJ: Dendritic cells: Immune regulators in health and disease. Physiol Rev 82: 97-130, 2002.

8. Blanco P, Palucka AK, Pascual V and Banchereau J: Dendritic cells and cytokines in human inflammatory and autoimmune diseases. Cytokine Growth Factor Rev 19: 41-52, 2008

9. Dowling D, Hamilton CM and O'Neill SM: A comparative analysis of cytokine responses, cell surface marker expression and MAPKs in DCs matured with LPS compared with a panel of TLR ligands. Cytokine 41: 254-262, 2008.

10. Neves BM and Cruz MV: Differential roles of PI3-Kinase, MAPKs and NF-kappaB on the manipulation of dendritic cell $\mathrm{T}(\mathrm{h}) 1 / \mathrm{T}(\mathrm{h}) 2$ cytokine/chemokine polarizing profile. Mol Immunol 46: 2481-2492, 2009.

11. Kim SF: The nitric oxide-mediated regulation of prostaglandin signaling in medicine. Vitam Horm 96: 211-245, 2014.

12. Aktan F: iNOS-mediated nitric oxide production and its regulation. Life Sci 75: 639-653, 2004.

13. Nakahara T, Moroi Y, Uchi H and Furue M: Differential role of MAPK signaling in human dendritic cell maturation and Th1/Th2 engagement. J Dermatol Sci 42: 1-11, 2006.

14. Chen RM, Chen TG, Chen TL, Lin LL, Chang CC, Chang HC and Wu CH: Anti-inflammatory and antioxidative effects of propofol on lipopolysaccharide-activated macrophages. Ann N Y Acad Sci 1042: 262-271, 2005.

15. Kim SN, Son SC, Lee SM, Kim CS, Yoo DG, Lee SK, Hur GM, Park JB and Jeon BH: Midazolam inhibits proinflammatory mediators in the lipopolysaccharide-activated macrophage. Anesthesiology 105: 105-110, 2006.

16. Peng M, Wang YL, Wang CY and Chen C: Dexmedetomidine attenuates lipopolysaccharide-induced proinflammatory response in primary microglia. J Surg Res 179: e219-e225, 2013. 
17. Ueshima $H$, Inada $T$ and Shingu K: Suppression of phagosome proteolysis and Matrigel migration with the $\alpha 2$-adrenergic receptor agonist dexmedetomidine in murine dendritic cells. Immunopharmacol Immunotoxicol 35: 558-566, 2013.

18. Ohta N, Ohashi Y, Takayama C, Mashimo T and Fujino Y: Midazolam suppresses maturation of murine dendritic cells and priming of lipopolysaccharide-induced thelper 1-type immune response. Anesthesiology 114: 355-362, 2011.

19. Brown M, Zhang Y, Dermine S, de Wynter EA, Hart C, Kitchener H, Stern PL, Skinner MA and Stacey SN: Dendritic cells infected with recombinant fowlpox virus vectors are potent and long-acting stimulators of transgene-specific class I restricted T lymphocyte activity. Gene Ther 7: 1680-1689, 2000

20. Dyck JB, Maze M, Haack C, Azarnoff DL, Vuorilehto L and Shafer SL: Computer-controlled infusion of intravenous dexmedetomidine hydrochloride in adult human volunteers. Anesthesiology 78: 821-828, 1993.

21. Swart EL, Zuideveld KP, de Jongh J, Danhof M, Thijs LG and Strack van Schijndel RM: Population pharmacodynamic modelling of lorazepam- and midazolam-induced sedation upon long-term continuous infusion in critically ill patients Eur J Clin Pharmacol 62: 185-194, 2006.

22. Gepts E, Camu F, Cockshott ID and Douglas EJ: Disposition of propofol administered as constant rate intravenous infusions in humans. Anesth Analg 66: 1256-1263, 1987.

23. Meng ZX, Li S, Wang L, Ko HJ, Lee Y, Jung DY, Okutsu M, Yan Z, Kim JK and Lin JD: Baf60c drives glycolytic metabolism in the muscle and improves systemic glucose homeostasis through Deptor-mediated Akt activation. Nat Med 19: 640-645, 2013.

24. Arend WP, Palmer G and Gabay C: IL-1, IL-18 and IL-33 families of cytokines. Immunol Rev 223: 20-38, 2008.

25. Inada $T$, Kubo K, Ueshima $H$ and Shingu K: Intravenous anesthetic propofol suppresses prostaglandin E2 production in murine dendritic cells. J Immunotoxicol 8: 359-366, 2011.

26. Ren K and Torres R: Role of interleukin-1beta during pain and inflammation. Brain Res Rev 60: 57-64, 2009.

27. Zelová $H$ and Hošek J: TNF- $\alpha$ signalling and inflammation: Interactions between old acquaintances. Inflamm Res 62: 641-651, 2013

28. Scheller J, Garbers C and Rose-John S: Interleukin-6: From basic biology to selective blockade of pro-inflammatory activities. Semin Immunol 26: 2-12, 2014.

29. González-Correa JA, Cruz-Andreotti E, Arrebola MM López-Villodres JA, Jódar M and De La Cruz JP: Effects of propofol on the leukocyte nitric oxide pathway: In vitro and ex vivo studies in surgical patients. Naunyn Schmiedebergs Arch Pharmacol 376: 331-339, 2008
30. Chen RM, Wu GJ, Tai YT, Sun WZ, Lin YL, Jean WC and Chen TL: Propofol reduces nitric oxide biosynthesis in lipopolysaccharide-activated macrophages by downregulating the expression of inducible nitric oxide synthase. Arch Toxicol 77: 418-423, 2003

31. Peng M, Ye JS, Wang YL, Chen C and Wang CY: Posttreatment with propofol attenuates lipopolysaccharide-induced up-regulation of inflammatory molecules in primary microglia. Inflamm Res 63: 411-418, 2014.

32. Chiu WT, Lin YL, Chou CW and Chen RM: Propofol inhibits lipoteichoic acid-induced iNOS gene expression in macrophages possibly through downregulation of toll-like receptor 2-mediated activation of Raf-MEK1/2-ERK1/2-IKK-NFKB. Chem Biol Interact 181: 430-439, 2009.

33. Lee CJ, Tai YT, Lin YL and Chen RM: Molecular mechanisms of propofol-involved suppression of no biosynthesis and inducible iNOS gene expression in LPS-stimulated macrophage-like raw 264.7 cells. Shock 33: 93-100, 2010.

34. FaugaretD,LemoineR,Baron C,Lebranchu YandVelge-RousselF: Mycophenolic acid differentially affects dendritic cell maturation induced by tumor necrosis factor-alpha and lipopolysaccharide through a different modulation of MAPK signaling. Mol Immunol 47: 1848-1859, 2010.

35. Nakahara T, Uchi H, Urabe K, Chen Q, Furue M and Moroi Y: Role of c-Jun N-terminal kinase on lipopolysaccharide induced maturation of human monocyte-derived dendritic cells. Int Immunol 16: 1701-1709, 2004.

36. Jin Y, Wi HJ, Choi MH, Hong ST and Bae YM: Regulation of anti-inflammatory cytokines IL-10 and TGF- $\beta$ in mouse dendritic cells through treatment with Clonorchis sinensis crude antigen. Exp Mol Med 46: e74, 2014.

37. Handley ME, Thakker M, Pollara G, Chain BM and Katz DR: JNK activation limits dendritic cell maturation in response to reactive oxygen species by the induction of apoptosis. Free Radic Biol Med 38: 1637-1652, 2005.

38. Kadoi Y, Saito S, Kawauchi C, Hinohara H and Kunimoto F: Comparative effects of propofol vs. dexmedetomidine on cerebrovascular carbon dioxide reactivity in patients with septic shock. Br J Anaesth. 100: 224-229, 2008.

39. Jakob S, Ruokonen E, Grounds RM, Sarapohja T, Garratt C, Pocock SJ, Bratty JR and Takala J; Dexmedetomidine for Long-Term Sedation Investigators: Dexmedetomidine vs. midazolam or propofol for sedation during prolonged mechanical ventilation: Two randomized controlled trials. JAMA 307: 1151-1160, 2012 